enseñanza de la técnica de nuestro deporte, especialmente si nuestros pupilos son niños y jóvenes. El autor intenta de este modo traer a nuestra memoria el proyecto educativo que Jigoro Kano elaboró cuando en 1882 fundó una nueva escuela de jiu-jitsu, el Judo, a la que precisamente cambio su nombre para hacer evidente que se trataba de algo distinto. Mas allá que un simple arte de lucha el Judo debía ser una escuela para la vida.

El autor propone a los profesores de judo recobrar ese reto educativo de educar para la vida a través de Judo, en una sociedad donde los valores y las normas éticas parecen haberse relativizado tanto que casi han desaparecido. Sin hacer grandes discursos, es posible percibir en el trato diario con nuestros alumnos una cierta desorientación vital, causada por escasez de claros referentes de conducta. Una especie de todo vale, de nada es mejor que cualquier otra cosa, de es lo mismo esto que aquello. Pero, no es así. Independiente de las posiciones individuales de cada uno, lo cierto es que los valores, unos más individuales y otros mancomunados con los demás, son importantes para el crecimiento individual y social.

El Judo, que como también cita el propio autor, ha sido recomendado por la UNESCO por sus valores educativos, es un buen camino para ofrecer a nuestros alumnos alguna ayuda en el camino de la vida. $\mathrm{Y}$ esto es algo que los profesores de Judo no deberíamos olvidar. Sin embargo, no se puede esperar que los valores se aprendan y se desarrollen porque sí. El Judo es un buen vehículo, pero todo vehículo necesita un conductor que sepa dónde dirigirlo. Este es el reto para el profesor de Judo. Según nos propone José Santos Nalda, el profesor de Judo debería hacer explicita esta tarea educativa en actitudes y valores e incorporarla a su programa de enseñanza junto con las habilidades físicas y técnicas. Para ello nos propone en su libro un conjunto de objetivos para la educación en actitudes y valores vinculados a cada etapa del aprendizaje en judo y una metodología de trabajo para tratarlos de forma explicita durante las clases de judo e incluso fuera de ellas con el apoyo de las familias. Este es sin duda el interés y la aportación de su libro.

Sin embargo, algo resulta un tanto desconcertante en la lectura de este sencillo libro, es que resulta difícil descifrar para qué lector está realmente escrito, pues parece que a lo largo del libro el autor se dirige indistintamente a los profesores de Judo y a los propios niños. Tal vez hubiera sido más acertado escribir un libro sólo para profesores o sólo para niños. O dos libros, uno para cada componente del tándem educativo profesor-alumno.

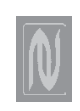

\section{Budo Mind and Body: Training Secrets of the Japanese Martial Arts}

Por Nicklaus Suino

Boston: Weatherhill, 2006

160 páginas, $14 \times 18,5 \mathrm{~cm}$. Ilustraciones.

I.S.B.N.: 08-3480-568-5 • \$16.95

Idioma: Inglés

Disponible en:

Shambhala Publications

P.O. Box 308 Back Bay Annex

Boston, MA 02117-0308

Toll-free Tel: 888.424.2329

Tel: 866.424 .0030

Fax: 617.236.1563

E-mail: custserv@shambhala.com

www.shambhala.com

\section{Revisión por John Donohue}

Nicklaus Suino se ha afirmado como un practicante y acreditado escritor de la tradición marcial japonesa. Escribe trabajos reflexivos y equilibrados sobre budo, y su último trabajo no es una excepción. Budo Mind and Body [Mente y cuerpo en el Budo], es, de hecho, una versión modificada de su trabajo de 1996 Arts of Strength, Arts of Serenity [Artes de Fuerza, Artes de Serenidad]. El libro actual contiene cinco capítulos cortos: Entrenando el Cuerpo, Entrenando la Mente, Cultura del Budo, Tres Virtudes Marciales, y Entrenando el Espíritu. En estas pequeñas secciones, Suino proporciona un análisis sensato y convincente del proceso de recorrer el camino marcial en las artes modernas japonesas. A pesar del entrecortado subtítulo editorial que insinúa los "secretos del entrenamiento", Suino hace un buen trabajo expresando cómo el estudio del budo es un proceso que requiere de disciplina, paciencia y esfuerzo. Los resultados pueden ser profundos y transformadores, como Suino cree claramente, pero su convicción de que estos resultados se consiguen a través del riguroso entrenamiento viene a ser un buen correctivo a las ideas populares sobre las artes marciales y las habilidades "como por arte de magia".

El autor hace unos acertados pequeños esbozos de varias artes marciales modernas como ayuda para los individuos que están considerando el dedicarse a estudiar una u otra. Este libro es, de hecho, una bonita introducción al budo para los individuos nuevos en el mundo del dojo. Tiene poca hipérbole y mucho sentido común y experiencia. Lo recomendaría como un trabajo apropiado para los estudiantes principiantes, aunque la claridad de la prosa de Suino y la sinceridad de sus convicciones en relación con los beneficios del estudio del budo lo recomendarían para cualquier lector que comparta algo con su experiencia y sus creencias.

Suino también proporciona una pequeña bibliografía al final del libro. Aunque compuesta con los títulos favoritos del autor, la lista se habría beneficiado de la inclusión de algunas referencias adicionales -hay, por ejemplo, trabajos introductorios más modernos y más logrados sobre kendo que el viejo libro de hace 40 años de Sasamori y Warner-, y los aficionados a la lectura se han beneficiado del trabajo de calidad sobre kyudo realizado por Deprosperos.

Como última objeción, aunque felicito a Weatherhill por su firme y continuado éxito produciendo trabajos de calidad en temas marciales, espero que consulten con la gente (así como con sus propios autores) antes de diseñar las cubiertas del libro. El magnífico libro de Suino tiene como portada la fotografía de un individuo vistiendo una armadura completa de kendo, y sosteniendo una espada de madera. Los practicantes de kendo usan el bokken, pero no hacen esto vistiendo el guante protector conocido como kote. E incluso el principiante más novel, en cualquiera de las artes con espada, podría haber dicho al fotógrafo que la espada de práctica se sostiene con el filo cortante hacia arriba. Estos tipos de errores probablemente hacen que un individuo experto, como Suino, rechine los dientes de frustración, pero debería descansar seguro de que, cualquiera que sean los 
defectos menores de la cubierta del libro, los contenidos son de alta calidad.

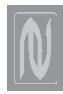

\section{Meditation and the Martial Arts}

Por Michael L. Raposa

Charlottesville, VA: University of Virginia

Press, 2003

192 páginas, $13,3 \times 20,3 \mathrm{~cm}$.

I.S.B.N.: 08-1392-238-0 • \$22.95

Disponible en:

The University of Virginia Press

Box 400318

Charlottesville, VA 22904-4318

Toll-free Tel: 800.831 .3406

Toll-free Fax: 877.288.6400

Email: vapress@virginia.edu

www.upress.virginia.edu

\section{Revisión por David O'Regan}

La obra de Raposa Meditation and the Martial Arts [La Meditación y las Artes Marciales] es un libro de dimensiones físicas modestas, aunque es grande en ambición y de riqueza en los contenidos. Raposa declara que su interés esta en "las artes marciales concebidas como practicas meditativas y en la meditación concebida como una disciplina marcial" (p. 2), y apoya sus impresionantes credenciales académicas con la experiencia práctica en las artes marciales. En su prólogo, el autor reivindica que sus habilidades en las artes marciales son "rudimentarias", pero confiesa su experiencia en una variedad de estilos, incluyendo el Aikido, Taijiquan, Iaido, y Tang Soo Do.

El estudio está dividido en cinco capítulos-los tres primeros ofrecen estudios de casos de los aspectos meditativos del Aikido; de las artes Taoístas de Taijiquan, Baguazhang, y Xingyiquan; y de ideas relacionadas con la tradición Hindu, Zen, e Islámica-. El cuarto capítulo trata del combate espiritual en la teología cristiana, y el quinto relaciona el tema de estudio con las escrituras de tres filósofos americanos -William James (18421910), Charles S. Pierce (1839-1914), y Josiah Royce (1855-1916) -.

Aunque los tres capítulos iniciales pueden parecer a primera vista meras repeticiones del conocimiento existente, el texto se yergue con nuevas percepciones sobre los temas objeto de discusión. De hecho, en casi todas las páginas del libro hay algo para estimular la mente. Para este crítico, los aspectos del análisis de Raposa más originales y que hacen reflexionar pueden encontrarse en las comparaciones entre las prácticas de meditación en las artes marciales asiáticas y la idea de guerra espiritual en el ascetismo cristiano. En particular, la espiritualidad marcial y los ejercicios meditativos de Ignacio de Loyola son un recuerdo de la universalidad del tema de la iluminación a través de las prácticas meditativas "combativas" y las disciplinas espirituales relacionadas (incluyendo el ritual y la oración).

Aunque el estudio de Raposa tiene mucho que elogiar, este crítico sostiene dos dudas. Primero, podría arquear las cejas ante las excesivas generalizaciones ocasionales del autor. Esto puede deberse al pequeño tamaño del libro, el cual limita el alcance para regresar a los principios de los temas mencionados de pasada. Tomando un ejemplo, muestra quizás una falta de crítica de la idea de las raíces históricas de Irán, a través del judaísmo helenístico, del gnosticismo (pp. 92-93). Esta idea de gnosticismo como originaria del Zoroastrismo tiene una sólida tradición intelectual entre los escolares orientalistas de los siglos XIX y XX de una rama "genealógica", pero ha sido discutida por los teólogos y los historiadores de la religión (como Karen L. King) quien pone en duda la idea misma del gnosticismo como un fenómeno histórico discontinuo. Nada de estos debates se recoge en la corta discusión del tema que realiza Raposa.

La segunda duda se refiere al aparente desconcierto en el tema central de este es- tudio, ya que se queda en la superficie al interpretar la comprensión del sentido de las experiencias de los practicantes orientados hacia el aspecto marcial meditativo. Leer el libro es como avanzar a tientas dentro de un pajar, sólo para encontrarlo en gran parte vacío en su esencia. $\mathrm{O}$, diciéndolo de otra manera, parece que las referencias basadas en libros, notas al pie de página, y la lógica magistral se disuelven en las extrañas sombras metafísicas proyectadas por las artes marciales meditativas. Esto podría sugerir al lector una limitación en la naturaleza de la empresa subyacente al libro de Raposa: el autor trae las herramientas del estudioso para analizar minuciosamente las áreas de experiencia que, discutiblemente, no son responsables de ser entendidas por el intelecto.

Si las experiencias de la actividad somática cargada espiritualmente son inexpresables en palabras -y el autor insinúa esto cuando declara en su prólogo que las comprensiones del Tao son "demasiado grandes para ser verbalizadas"- y si uno acepta que esta inexpresividad es intrínseca a la meta final del camino marcial meditativo, cualquier análisis intelectual necesariamente no llegará a su objetivo. El enfoque académico simplemente no puede extenderse por las artes marciales meditativas como una marea de espuma a través de las cavernas de la orilla y, retrocediendo, dejárlas desnudas y despojadas de misterio.

Sin embargo, reflejar estas dudas es evidenciar una tibia protesta. El intelecto debería ser tolerante con lo misterioso y debería buscarlo y no esconderlo o suprimirlo, antes al contrario, intentando vivir en paz con él en una relación de influencia mutua. Y Raposa ha conseguido esto en gran medida. Dentro de las limitaciones inherentes de un trabajo que intenta intelectualizar lo que sólo puede ser entendido más allá de los confines del intelecto, Raposa ha escrito el mejor y más accesible estudio académico sobre el tema. 